\title{
Social Media Role in Relieving the Rohingya Humanitarian Crisis
}

\author{
Fatma Elzahraa Elsayed* \\ Associate Professor, Faculty of Mass Communication, Cairo University.
}

\begin{abstract}
This research explores the possibilities and limitations associated with utilizing new media technologies in relieving humanitarian crises by focusing on the Rohingyan case. The main interest is to approach a conceptual communication framework based on the current Rohingya refugees' perceptions about social media networks and mobile apps and the potential suggestions to optimize its usefulness in relieving their crisis. Addressing the obstructive challenges that interrupt the new media technologies functionality is another objective of the study. The mixed methodology interlaces the qualitative findings of the questionnaire with the qualitative outcomes of the semi-structured interviews to reach an inclusive investigation to the research questions. An examination to the significance of relationships between Rohingya demographic attributes and their preferences and perceptions toward social media platforms and mobile apps is substantial to explore the dominant factors that may influence the relationship between the Rohingya and different media platforms.
\end{abstract}

Keywords: social media, mixed methods, Rohingya, humanitarian crises

DOI: $10.7176 / \mathrm{NMMC} / 87-04$

Publication date: January $31^{\text {st }} 2020$

\section{Introduction}

Having a communication plan is essential to the success of any crisis management process regardless of the type of the crisis. There are a variety of crises such as natural disasters, economic or political instability, military conflicts, etc., that need a communication framework to keep an effective connectivity and easy flow of information and knowledge transmission among the main involving parties. The communication plan should aim to handle the crisis mindfully to pave the road to a comprehensive solution. The humanitarian crises are among the most critical cases that require a fast and efficient reaction as it directly influences human life.

This research focuses on the new media applications that can effectively contribute to solving humanitarian crises. The main objectives are to explore the existing possibilities of new media technologies in solving the humanitarian crisis of the Rohingya people, define the opportunities to reinforce the new media implications in relieving distresses, and reform catastrophic conditions. Moreover, this study aims to approach a cooperative profile of civilian and governmental integrated participation for removing the suffering of the distressed people. Briefly, the research is an attempt to answer the following three questions:

1- $\quad$ How the Rohingya refugees evaluate the functionality of social media networks and mobile apps in relieving their humanitarian crisis?

2- What are the Rohingya refugees' suggestions to maximize the usefulness of social media networks and mobile apps in relieving their humanitarian crisis?

3- What are the limitations that Rohingya refugees believe it obstructs the effective employment of social media networks and mobile apps in relieving their humanitarian crisis?

\subsection{Brief Overview of the Rohingyan Crisis}

The Rohingyan case is a clear shocking example of the tragic consequences of political oppression and injustice. (Wade, F. 2017) The problem that makes this crisis more complicated is the world unjustified and unaccepted silence that lasted for decades toward the systematic cleansing and hidden genocide campaigns committed by Myanmar military authorities. (Ibrahim, A. 2016) Since 1948, the Rohingya was enjoying full citizenship rights in Myanmar, which was controlled, at that time, by the British administration. They had representatives in the parliament, ministers, and high government position personnel. During the WWII, the Rohingya people supported the British army and the allies' troops against Japan. The Japanese military created resistant groups called "Tatmadaw" to fight against the Rohingya people. After the WWII, "Tatmadaw" military groups started to violate the Rohingya human rights and keep on arbitrary acts that have been accelerated after 1964 when "Tatmadaw" took over the authority in Myanmar by a military coup. (BRC., 2018)

The political oppression and tyranny of the Myanmar military authorities against Rohingya people reaches one of its peaks in 1982 when declaring the full cancellation of the Rohingya citizenship and to left them as one of the largest stateless minorities in the recent age. (Abdul Bari, M. 2018) In 1991, more than 250.000 Rohingya refugees flee to Bangladesh to avoid Myanmar Army violence and human rights abuses in Maungdaw. Between 1993 and 1997, 230.000 refugee return to Rakhine. A new wave of violence exploded in 2012 and resulted in the displacement of 140.000 . Around 120.000 remained in internally displaced person camps in Rakhine. Claims that some Rohingya militants attacked border guards resulted to 74.000 Rohingya crossed from Rakhine state into Cox' 
s Bazar between Nov. 2016 and Feb. 2017. A UN investigation conducted to verify alleged human rights abuses committed by the Myanmar Army against Rohingya.

The massive refugee explosion of the Rohingya people took place in August 2017 directly after a visit of the Rakhine commission chaired by Kofi Annan, the former UN secretary that recommended to take all possible measures to stop violence and improve security in Myanmar. (Patel, C., 2018) The refugees reported that the Myanmar military with Buddhist civilians of Rakhine state has beaten, tortured, raped, and hacked to death numerous of Rohingya civilians including women and children. This horrific situation forced over half million to leave their homes and lands and move on foot or by boat to Bangladesh. In September 2017, the UN reported that 120,000 of Rohingya had fled Myanmar to Bangladesh and the UNHCR estimated the numbers in the middle of September as half million refugees gathered on overloaded camps. (UNHCR, 2018)

The UNHCR issued a humanitarian response plan in Oct. 2017 to be applied between September 2017 and February 2018. The operational response includes essential relief sectors such as, education, food, security, health, logistics, nutrition, protection, site management, water \& hygiene, and communicating with communities (CWC). The communication plan detected a severe need to supply life-saving information to the Rohingya communities in Bangladesh in an appropriate format that facilitates access to services, eliminates risks, and develop behavioral change. UNHCR detected that the host communities that receive new Rohingya arrivals need information about the existing conditions to lessen the prospect risks of conflict, violence, rumor, and the possible tension inside the host communities. (UNHCR, OCT 2017)

\subsection{New Media Technologies Role}

The expected role of the new media technologies in relieving humanitarian crises is undeniable. However, each media platform has preferential tasks can be accomplished by using it better than the other platforms. It is argued that the communication during crises should address perceptions. (Wendling, C. et al 2013) The process of proposing ideas includes an extensive ability to demonstrate proves, claims, reasons, and evidences with unlimited opportunity to link supportive material. Facebook and YouTube are efficient social media platforms in constructing and changing perceptions and they've been intensively employed to spread hatred speech that played an essential role in fueling violence that targeting Rohingya. (Samet, O. 2018) The UN fact finders have detected that Facebook has a fundamental and determining role in boosting anti-Rohingya feelings inside Myanmar. (Meixler, E. 2018) The deconstructive role of Facebook can be flipped to spread peace, understanding, and forgiveness instead of hatred and violence. Twitter has different advantage; it is mainly a tool to draw global attention to an issue at a given time through viral hashtags. In August 2017, 1.2 million tweets have been posted including words like "Rohingya", "Myanmar", "Burma", and hashtags included "\#Rohingya_Muslims", “\#Pray_For_Rohyngya", "We_are_all_Rohingya”. (Rannard, G. 2017).

In times of catastrophes or severe humanitarian crises, the need to receive accurate information becomes crucial. The Rohingyan case shows that using WhatsApp as an audio visual communication mobile app is effective in connecting afflicted people with each other and keeping them in touch with the news of their homeland. WhatsApp fills the information gap as it doesn't need high level of education and it can be operated on cheap mobile phone uses solar energy to charge its batteries. The challenge in using WhatsApp communication is that there is no an applicable method to distinguish between facts and fake news. The trustworthiness is not verifiable so that the distressed people may receive misleading messages contribute in complicating the crisis rather than relieving it. (Lewis, S. et al 2017)

The main contribution of this research is to explore the perceived role of new media tech and social networks that the Roingyan people believe in relieving their humanitarian crisis. It is an in-depth analysis of their own point of view in utilizing the media tech and how the ethnographic attributes influence their opinion. The significant point in this research is that it may define some future possibilities to employ social media networks in similar circumstances. As we should consider that each disaster has its unique conditions, socially, politically, and geographically. These conditions determine the potential solutions and the expected cooperation from different parties.

I believe that this research worth to be done for many reasons. First, the sanctity value of the human being's life and the importance of any efforts could be exerted to save it or to secure a respectful treatment to it. This is one of the principle human rights that have been historically documented and adopted by the UNGA on the universal declaration of human rights (1948) and widely accepted by most of the human ideologies and celestial religions. (Donnelly, J. 2003, 2017 and Steiner, H. 2007)

Secondly, the variety of possibilities in communication and information technologies that is highly significant to be illustrated and highlighted to investigate its beneficial applications for solving humanitarian crisis. The collaboration between disaster relief organizations and Human Sensors Networks platforms does not need to wait until disaster strikes, majority of HSN is done purely by volunteers and consists of key entities: sensors, reliability, and GPS. (Yuan,W. et al 2013, Merchant, R.M et al 2011, Weiss, A.S.2013)

Thirdly, empowering people with communication technologies is one of the main pillars of the modern 
democratic societies. The technologies supporting citizens should be horizontal, semi structured, real time, open, geo-aware, accessible, high quality in terms of sensitivity and specification. (Kamel, M.N. et al 2011 p24, 25) In addition of the significant implications of communication technologies in healthcare, health-reporting, and social well-being issues (Mesmar, S. et al 2016, Freifeld, C.et al 2010) and effective surveillance system for road traffic (Bonnet, E. et al 2017).

Fourth, employing new media technologies for solving humanitarian crisis would positively contribute in building national peace and boost the international security. (Puig Larrauri, H. \& Kahl, A., (2013)., Wachanga, N. 2015)

Fifth, the research aims to emphasize the concept of employing new media technologies for humanitarian and idealistic purposes against the dominant concept of using information and communication technologies for commercial or private purposes.

To sum up, the purpose of this research is to investigate the potential implementations and limitations of social media networks and mobile apps in relieving the Rohingya humanitarian crisis and to suggest possible applications that can support emergency response of the governmental and non-governmental organizations. A questionnaire will be distributed to the Rohingya refugees settled in Bradford/UK to explore their evaluation to the functionality effectiveness of new media technologies interacting with their crisis. Moreover, interviews with key persons of the British Rohingya Community in Bradford and the Rohingya refugee activists in Bangladesh camps aim to give an in-depth explanation to the possibilities and limitations of utilizing new media technologies in relieving humanitarian crises on the short-term operations and on the long-term strategies.

\section{Literature Review}

In this section, a brief overview about the position of the humanitarian crises management studies within the communication research is presented and followed by an explanation of the multiple ways to understand the implications of social networks and new media applications in relieving crises and mitigating the destructive consequences of the natural disasters or human conflicts. We can imagine the usefulness of the social media when looking back and know that the voice of the victims in any humanitarian crises was absent, however, they are the central source of information and their testimonies and suggestions are essential to reveal the facts and plan for rescue operations. (Coonrood, J. 1997)

It is important to outline some of the creative experiences to use social media and produce original ideas to utilize different types of communication technologies generally in crisis management and particularly in humanitarian crises. The political variables intervention in any humanitarian crisis is determinant. Therefore, it is essential to explore the political measurements that can be applied by the governmental authorities or the lobbyists that influence the political decision to avoid any potential escalation or to offer possible solutions and facilitate organizational coordination. The Rohingya humanitarian crisis is an example of the usefulness and limitations of using social communication networks and new media technologies in different stages of the crisis.

\subsection{Humanitarian Crises in Communication Research}

Towards achieving a higher level of efficiency and competitiveness in manufacturing operations, the European Community (EC), European Free Trade Association (EFTA), Australia, Canada, Japan, and the United States (US) founded an international collaborative research programme called Intelligent Manufacturing Systems (IMS) in 1993. This programme consists of six major projects, wherein the fifth one is entitled "Holonic Manufacturing Systems: system components of autonomous modules and their distributed control". It is important to emphasise that HMS does not represent a new technology, as it is merely a conceptual modelling approach to connect and make use of existing technologies with human interfaces (McFarlane 1995). HMS became one of the first fully endorsed IMS projects in 1997, and so the International HMS Consortium was formed and dedicated to replicate in manufacturing the strengths that holonic systems provide to living organisms and societies. These holonic strengths encompass stability in the face of disturbances, adaptability and flexibility in the face of change, and efficient use of available resources. Succinctly, autonomy and cooperation are known as the prime attributes of HMS (Valckenaers et al. 1997; Bongaerts 1998).

\subsection{Social Media Applications}

We can observe many individual and organizational attempts targeting to suggest social networks and new media tech formula that effectively contribute in relieving humanitarian crises. One of these attempts is the "Standby Task force" (SBTF) which newly classified as a type of the "Digital Humanitarianism". The digital humanitarianism is a type of media intervention in the humanitarian crises aims to coordinate efforts in a decentralized form based mainly on volunteers. (Norris, W. 2017) The standby task group force utilizes the crowdsourcing entities, expert communities, and infrastructure technical mobile applications.

"Apollo Fact-Finder" is one of the leading projects that aims to mitigate one of the obstructive problems that eliminates the potential usefulness of social media information through reliability examination of the sources and 
credibility investigation of the claims published using big data streams. (Kase, S. E et al 2014) The data of the project was collected in August 2013 after the Syrian chemical weapons crisis and revealed significant polarization in the political stances. The findings emphasize the data verification as an essential procedure to enable politicians make well-informed decisions.

Verification of data across social media is a serious issue. A tweet monitoring system is created to identify messages that individuals post during crises into a group of informational classifications using a Lip-Linear identifier that extracts the texts that include calls of action through a Natural Language Processing system. The accuracy average of this system constitutes $75 \%$ during the Myanmar earthquake 2016. Lip-Linear Identifier is a classification system designed to monitor tweets relevant to a certain crisis by following updates that people post and categorize the extracted information in three groups, "informative", "not informative", and "other information". The system produce crisis related databases with new tweets and make an online identification. The significance of this system is that it is a progressive technique for retrieving and filtering information published about disasters as it practically overcomes the major problems of classifying tweets into certain informative datasets. (Win, S.M \& Aung, T. N. 2017)

The European Commission sponsored project "COSMIC" (1) combines the theoretical and field applications in an integrated framework to maximize the potential utilization of social media in protecting people and examine their possible involvement in the emergency response relying on three principles; the appreciation of civil society as source of information, trusting the ability of the people to preserve their own well-being, and promote public capacities to communicate effectively with social media networks through civil society organization. (Baruh, L. 2015) In a study focused on the role of communicators to improve social media utilities to enhance managing crisis, group of "NCFPD"2 and US department of homeland and security researchers identify some guidelines for better response include plan pre-event logistics, a partnership with the public, listen directly to the afflicted people concerns, communicate with honesty and empathy, accept uncertainty, and provide messages of self-efficacy. (Veil, S.R. et al 2011)

It is crucial in some humanitarian crises to locate victims and visualize their conditions for the purposes of making rational humanitarian and political decisions. The crisis mapping is an effective technique to easily report and share digital geographic information. (Brandusescu, A. \& Sieber, R.E. 2018) It enables large number of people to communicate online and coordinate rescue and relieving efforts. Similarly, the "Micro-Mappers" (3) is an application that categorizing tweets by labeling them to detect and collect the instructional procedures related to the infrastructural damages, the community needs, and the nature of humanitarian support. (Veil, S. R. et al 2011) Nevertheless, it is important to consider geographical differences that may affect the accuracy of data collection process. A comparative study of geographic granularity between Myanmar and Italy earthquake events indicates that the provided information about nearby places in the case of Myanmar was remarkably less than Italy. (Zahra, K.et al 2017) The problem is that well-informed relieving decisions become more accurate when details are available, otherwise the relieving operations could be less effective.

A practical framework to control social media feeds during crises suggests to identify topics by relevant \#hashtags and create teamwork for filtering and validating tweets, stress on the criticality of geo-locating posts that consider security conditions, and the great usefulness of translating from different languages rather than English. (Appasi, M. A. et al 2012)

The organizations can receive positive responses via its social media platforms by applying a "Technical Translation Strategy" to communicate with affected people, rather than applying a "Crisis Response Strategy". (Chung, Surin \& Lee, Suman 2016) This indicates the need of the people in times of certain dangers to be informed in clear and concise messages how to protect themselves and minimize the potential risks rather than receiving messages that aim first to repair reputation of organizations or justifying disasters and giving excuses to tolerate the actors. such strategies received negative reactions on social media platforms. (Chung \& Lee 2016)

In a triple study examined the social media users' behavior during and after disasters (Neubaum, G. et al 2014), a direct correlation between the active engagement of individuals in social media communication and the feeling of positive emotions was revealed. Positive emotions like not being alone and ability to overcome terrible experience associated with sudden dramatic situations were observed among Facebook, YouTube, and weblogs users. The results indicate that information seekers during disasters are not only looking for detecting facts and gathering date, but also interested in sharing people's internal states and discuss their feelings and thoughts. (Neubaun, G. et al 2014. p 37)

Veil, S. R. et al (2011) demonstrate number of recommendations that can be useful to organizations that employ social media platforms to communicate during crisis. The second level analysis applied in this study emphasized on the role of social media to assist organizations in following best practices in times of disasters. Some of these recommendations include determination to engage with social media at daily basis and make it as

\footnotetext{
1 - The Contribution of Social Media in Crisis Management, http://www.hrt.org.gr/8A9D74BF.en.aspx

2 - National Centre for Food Protection and Defense.

3 - An online platform based on volunteering participation to read and label social media information.
} 
a part of the risk management, employ social media tools to know more about affected people through listening and discussing their cases, deciding the best channels to communicate with publics in different circumstances, verifying information to respond accurately to the questions, sharing messages with credible sources, and interact with social media as a first step to update information. (Veil, S. R. et al 2011. p 119-120)

The Haiti earthquake crisis in 2010 is a good example of the social media utilization to relief the afflicted people. The US relief agencies employed media technology such as Wikis and collaborative workshops based on knowledge management system through social networks to provide an assistant (3-T) model consists of three dimensions: The syntactic transfer, the semantic translate, and the pragmatic transform. The first dimension focuses on sharing knowledge with involved organizations or humanitarian workers to avoid the information duplication and foster data accuracy. The second level main function is to optimize knowledge usability and visibility. The third mission is establishing connections with external resources through conversations and knowledge transformation. (Yates, D. \& Paquette, S. 2010)

The department of Homeland Security cooperated with the movement of social media disaster relief to create Haiti social disaster monitoring initiative that carried out the responsibility of following up the involved websites to cover and report the disaster conditions and coordinate with the government agencies in the country. (Slagh, C. L. 2010) There are three dimensions in which social media assist effectively in the Haiti crisis includes employing the technical search to improve rescue operations, extending the possibilities of volunteers' participation, and enhance the accessibility of the news channels to keep Haiti's people in touch with the news coverage. The Haiti disaster experience emphasizes the crucial role of the government interfering in the relieving operations and in coordination with NGOs and volunteers. On the contrary, the Rohingya people are not only deprived of the government assistance but also affected by the obstructive procedures of the Burmese authorities against the them.

The decision making process in the humanitarian crises is a large-scale operation, (Kamissoko, D.et al 2014) suggests four phases to manage this operation starting with a decision making characterization, then modelling of the system, aggregating all sources, and the last phase is integrating and coordinating all efforts.

The role of the citizens' communication is crucial during humanitarian crisis, but the key factor to maintain a successful relationship in cooperation and coordination with other involved entities is "Trust". (Watson, H.\& Hagen, K. 2015) The Trust is an essential element to preserve a framework of collaboration between citizens and organizations before, during, and after the crisis. The catastrophic accident of the flight MH370 of the Malaysian Airlines constitutes a model of citizens' partnership in producing and sharing information through crowdsourcing utilities. The effective participation of the citizens based on trust and positively helped in the crisis management. Before the crisis escalates, comprehensive information should be delivered to the citizens and after the crisis there should be a rational utilization of social networks and new media technologies to strengthen the community resilience and ensuring that the crisis is over and everything is settled down. Trust in citizens leads to trust the information they produce. (Tapia, A. H. \& Moore, K. 2014) In some crisis's's situations, especially in the emergency cases, it is possible to operate with "Good enough" or less than reliable information. Trust here is relying on the people, not on the data. Moreover, the non-competitiveness nature of the organizational work during humanitarian crisis increases the potential of inter-organizational information sharing.

The information posted earlier during the disasters has stronger probability to be transmitted in a higher speed than later information. The participants in information diffusion increase overtime and compete in publishing. (Yoo, E. et al 2016) The media actor celebrities play a major role in accelerating the speed of information diffusion during humanitarian crises as their fans and followers participate in the same mission.

The involvement of the citizens in the crisis management and collaboration with the media in relieving efforts during humanitarian issues includes some guidelines that foster the expected results. (Aggeraard, S.P. 2015) For example, moving fast and consider the preset deadline of some media services, being proactive and use all possible means of communication, being on the focus and deliver information in points, and take care of the recording conditions to produce appropriate material.

The citizens' reactions to the humanitarian response differ in terms of their age and perceptions of the threat level. (Lyn, J. C. 2012) There is an evidence that young people are more vulnerable to be influenced by the media networks information for purposes such as social understanding, social play, solitary play, and common goals. It is interesting to notice that "playing" is one of the young Chinese main uses of media during crises. This can be interpreted as a psychological defense to overcome the stressful effects of the crisis peacefully.

\subsection{Social media and politics in Humanitarian Crises}

There is an evidence that the political, national, and social factors play a determinant role in formulating the public awareness toward different issues. (Glynn, C. J. 2016) It contributes in constructing attitudes and build the images of the individual and organizational entities especially when the media apply a political agenda through a longterm strategy. (Clawson, R. A., \& Oxley, Z. M. 2013) The humanitarian crisis explosion moment is not the starting point of the story. Actually, it is the conclusion point in which the media demonstrates its role in paving the public consciousness to accept or at least not to resist the potentially dramatic consequences of the humanitarian crises. 
On the other hand, (Bennett, S. 2016) argues that policy shifts are sometimes reaction to discursive shifts that occurs in response to the wide circulation of news reports or images in the social media and then in the international big media mainstream. The photo of Aylan Kurdi's dead body on the Turkish shores is an example of how the mediatization of the migrants' plight can convert the potential negative attitudes to an empathetic feeling. The media also can cause an external political or military intervention which known as the CNN effect. (Robinson, P. 2000). In the Syrian Refugees crisis, there is a claim that the media formed a constant pressure to derive political decision-making response from many actors. (Doucet, L. 2018) one of the main conclusions is that the media do not make a strategy but plays a significant role in directing the events. Furthermore, a comparative study of the textual messaging on Pinterest and Instagram about the Syrian refugee crisis claim that improving the visual representation of the refugee crisis in addition to adopting thematic framing strategy could be effective in developing the public response for humanitarian crises that drive the political intervention. (Guidry, J. P. D. et al 2018) It also shows that the security-concern posts have been classified thematically, however, the humanitarianconcern posts framed episodically.

From different perspective, a comparison between the refugees' tweets in the Turkish and Belgium national contexts shows that the interpretations of the same images differ massively when approaching a certain national context that influenced by the nature of the political landscape, the history of national migration, and the selfexplanatory victimization common logic. (Bozdag, C.\& Smets, K. 2017)

The "othering" discourse is one of the key elements that impact the public consciousness profoundly to the extent that it may alienate the image of individuals or groups. The consequences of the "othering" discourse have been analyzed in the articles of the NYT from 1969-2014 to prove that radicalization speech is a product of sociolinguistic and historical development and not new as assumed. (Silva, D. M. D. 2017) The findings highlight that media employ discursive strategies to visualize Muslims as an "alien other" to the west. The western media stereotyping Muslims as terrorists, misogynist, violent, and enemies of the western freedom and civilization. (Ferre, J.P. 2014) the direct consequences of this discourse are the obstruction of Muslim who seek for asylum as an escape from the persecution in their home countries.

Similarly, the Indian media framed the Sikhs as violent, pre-modern and dangerous to the Indian state during the Punjab crisis 1983-1984. (Mann, R.D. 2016) The findings show that the Time of India newspaper portrayed them as religious extremists targeting to divide the unity of the Indian society and they are incapable to act rationally in the modern world. Spreading rumors sometimes constitutes a political action that leads to humanitarian crisis. A study argues that rumors targeted ethnic community in the technological hub of Bangalore in India led to mass exodus of fifteen thousand members of the targeted group. It claims that the government can play determine role in eliminating the rumor or contributing in its dissemination. (Oh, O.et al 2018)

The critical issue in the "othering" discourse is that it constitutes the primary stage in the genocide pyramid. In the Rohingyan case it was clear that the media discourse operates through a systematic strategy to move the public consciousness from stage to another gradually to destroy any resistance to Rohingya cleansing. The genocide pyramid starts with classifying and define a group as "others", symbolling them with certain features, discriminating them with inequality constraints, dehumanizing them, persecuting, denial, and genocide.

The politicians use of social media during a crisis is an arguable issue. Politicians can employ social media to communicate with publics and open conversations about current crises. The politicians/publics interaction may produce a well-informed and clear unified vision of possible solutions. On the contrary, there is an evidence that politicians prefer personal investment rather than discussing common affairs. A study concluded that Latin American politician employ their accounts mainly for self-promotion and "me now" posts rather than establishing conversations with the publics. (Segado, B. et al 2015) Another claim about politicians' employment to the social media in the current industrial democracies that publishing their private life events would familiarize their public image and generate a kind of intimacy they may rely on to drive political support. (Stanyer, J. 2013) A gendered comparison between the capability of males and females' politicians to generate more social media engagement during their election's campaigns. The findings indicate that females are more capable to enrich potential voters' engagement in terms of the number of links and shares more than the male politicians. (Yarchi, M. \& SamuelAzran, T. 2018)

From a wider angel, social media platforms can be employed to revive the national spirit and unite the citizens' efforts to confront a natural disaster that may devastate some ethnic groups have been considered for a long time as a different community. (Wachanga, N. 2015). National pride and belonging to one land are a strong incentive can motivate publics to participate in any humanitarian initiative to save people's lives or relief their suffering from draught and famine. Social media as an essential power in the public's hands can be a channel to deliver their message to the official and political authorities that the people have the power to change the reality without their interference. The framing analysis is applied to highlight the study objectives and it is also essential to emphasize on the impact of news story narration that attract public's attention through four processes include media placement, identification potential, narrative arc, and discursive space. (Fine, G.A and White, R.D. 2002. p 57, Moeller, S.D. 2002) 
From another perspective, there should be clear instructions, available guidelines, and accessible procedures to be followed by the news reporters acting in dangerous places or within oppressive contexts to protect themselves and continue covering stories with keeping credibility and efficiency. Covering stories in Arakhan state is type of conflict reporting that involves many challenges. Reporters are distinctly vulnerable to harassment, threatening, and kidnapping. (Kawoosa, V.M. 2015) Major problems in accessing information and preserve impartiality encounter the news reporters' practices and sometimes massively interrupt their work when the empowered authorities decide to suspend mobile telecommunications and internet services to tighten its control on the targeted region. It is essential, first, to be fully aware of the underlying causes of the conflict and its developments across time. Not to accept myths or allegations as facts and prioritize scrutiny over the scoop. Satellite phone keeps reporters in touch in cases of suspended telecommunications. (Webster, M. 2015) Taking all possible measures to protect journalists helps them report objective and truthful news stories that inform world public opinion about the situation and contribute in rational the political decision-making process that may lead to a crisis solution.

The crowdsourcing platforms construct a relationship between citizens and disasters. (Asmolov, G. 2015, Falcioni, John G. 2011) Ushahidi is one of the open source applications that allows anyone from any location to report an emergency. It is a "field of struggle between top-down taxonomies and bottom-up folksonomies". (Asmolov, G. p 19) It was employed by international media like BBC, The Guardian, Al Jazeera, Huffington Post to report testimonies about conflicts and crisis in different parts of the world. (Sandoval, T., and Oscar Espiritusanto. 2015) Similarly, Twitter hashtags contribute in linking the user with the disaster in terms of locating the victims, describing the situation, providing the activity, and defining the function. Ushahidi played a transformative role during Kenya's electoral violence in 2008 through crisis-mapping, early warning multi-agent consortium, and election monitoring. (Ajao, T and Wielenga. 2017)

Ushahidi is a mapping software initially located in Kenya and has been deployed in the democratic republic of Congo, inviting people to report incidents of violence in an online map. It played a prominent role during the earthquake disaster in Haiti 2010 and reported critical information about the affected population and facilitate fast data exchange between actors to support rescue operations. (karathanasi, M. et al. 2014, Dickinson, E. 2009, Falcioni, J.G. 2010, Ruffer, G. 2011 p 11) The major challenge facing the crowdsourcing apps is the overwhelming conditions of displacement that may confuse managing the submitted reports from certain places. For civil society organizations, the perception of relative advantages, compatibility, and complexity are significant predictors for adopting it and integrate it with its activities. (Tully, M. 2015)

Learning how to define locations accurately needs acquiring new skills related to cartography. (Liu, S. and Palin, L 2010). Social media users should involve in neo-geographic practice to improve their locating knowledge using the power hybrid forms. The crowdsourcing software not only contribute to narratives of how conflict was understood, but also to the narrative related to transforming the conflict and increase the number of ways people can participate in peace conversations. The "Peace Building" is one of the sociopolitical consequences of using crowdsourcing apps as providing maps of urgent events facilitates the immediate humanitarian response. (Kahl, A. and Puig Larrauri, H. 2013) Increasing the access of marginalized categories to information sharing and gathering would help empowering them and support "Peace Building" processes. (Vericat, j. 2010) It is argued that implications of crowdsourcing software would democratize the political life for marginalized categories of any society. Adopting ICT applications will build "self-created spaces" that plays its role not only as arenas to accommodate new type of politics but also to open possibilities to promote the state's capabilities. (Thigo, P. 2013 p 255)

\section{Methodology}

The purpose of this research is to investigate the potential communication model that comprehensively interact with the humanitarian crises based on the vision and evaluation of the affected people. Therefore, the methods used to investigate this issue are designed to answer three questions:

1- How the Rohingya refugees evaluate the functionality of social media networks and mobile apps in relieving their humanitarian crisis?

2- What are the Rohingya refugees' suggestions to maximize the usefulness of social media networks and mobile apps in relieving their humanitarian crisis?

3- What are the limitations that Rohingya refugees believe it obstruct the effective employment of social media networks and mobile apps in relieving their humanitarian crisis?

Moreover, the research investigates two main hypotheses the verify probable relationships between the demographic variables of the Rohingya and their perceptions about usefulness of different media platforms and preferences of ranking these platforms. The two hypotheses are:

$\mathrm{H}_{1}$ - There is a relationship between the demographic variables of the Rohingya and perceptions about media platforms usefulness for their issue. $(\mathrm{a}<0.05)$

$\mathrm{H}_{2}$ - There is a relationship between demographic variables of the Rohingya and their preferences of using media platforms. $(\mathrm{a}<0.05)$ 
This study relies on the pragmatism point of view that is not committed to any one system of philosophy and considers the truth is what works at the time. (Creswell, J. W. 2009) The analysis would apply the mixed methods approach in its concurrent triangulation design (CTD) that combine the data collection of qualitative and quantitative methods with the data analysis of both methods and then compare the data results. (Creswell et al. 2007) The interviews with key persons in the British Rohingya Community in Bradford/Uk that represents the international voice of the Rohyngia community constitute the qualitative part of the study, however, the questionnaire constitutes the quantitative part.

\subsection{Research Instruments}

As the research strategy followed the mixed methods design, two methods are used to investigate the main three questions of the study, the questionnaire, and the interview.

\subsubsection{The Questionnaire}

The purpose of the questionnaire was to investigate the current perceptions of the Rohingya refugees about the possible utilization of social media networks and mobile apps in relieving their crisis. Also, to explore any significant relationships between the demographic variables of the Rohingyas and these perceptions. The questionnaire was manually distributed and started on the 14th of April and completed on the 5th of May 2018. The targeted participants of the questionnaire were the British Rohingya Community (BRC) located in Bradford, UK. The most accurate number of the Rohingya community is 500. They were allowed to settle in Bradford as an implementation of the Gateway Protection Program (GPP) which is an organized migration plan administrated cooperatively by the Home Office, UNHCR, and the international organization for migration. The application of the program started in December 2008 to date and different nationalities benefited including the Rohingya, Ethiopia, Iraq, and Somalia. ${ }^{(1)}$

The total number of respondents from the Rohingya is 130. At the first stage of data collection, we aimed to reach 150 participants, but not all of them responded correctly to the questionnaire which was designed mainly to explore the possibilities of using new media technologies to relief their crisis. The topic requires a minimum level of culture and awareness that was not applicable to some cases.

The questionnaire consists of 23 questions in six pages and includes five sections. The first section is to define the major demographic characteristics of the respondents such as age, gender, education, occupation, residency, besides the social media daily usage duration and the order of the media sources about Rohingya news. The second section was to explore the Rohingyas convictions about mobile apps usefulness and the perceptions about the potential implementations to interact with their crisis. Many mobile apps were designed to relieve the humanitarian crises and execute different functions such as Ushahidi, UNHCR Emergency Handbook, UNHCR Refugee Site Planning, Relief Web-Headlines, GPS coordinates converter, Relief Web-Crisis, Relief Web-Jobs, Relief WebCrises Tablet, IOM Emergency Manual, Disaster alert, and Relief Central. The mobile apps provide many services that facilitate life for the distressed people and improve their conditions, such as enabling communication in time of crisis, allowing basic connectivity with family members, transferring cash and providing digital money, ensuring identity and eligibility for receiving aids e.g., barcode technology, accessing utilities (e.g., lighting) in case of service network failure, keeping in touch with the local and international news, Coordinating rescue and relief operations with relevant organizations.

The sections from the third to the fifth are investigating the Rohingyas convictions and perceptions about using YouTube, Twitter, and Facebook. The social media networks can be used to accomplish many tasks that substantially foster the Rohingya capacities in relieving their crisis, such as creating global awareness about their issue, demonstrating their testimonies, correcting the potential misunderstanding about the historical reasons and developments of conflict, mobilizing the world public opinion to derive a supportive political decision, spreading love and peace values among world nations, and improve wellbeing and stamina for existence. All sections have open-ended questions to enable respondents adding comments, examples, and reasons for disagreement.

3.1.2The Interview

The main purpose of the interview was to investigate the activists and experts' vision about the prospect role of mobile apps and social media networks in relieving the humanitarian crisis of the Rohingya. Eight interviews were conducted on scattered dates between April and August 2018, half of them were before analyzing the questionnaire findings and the rest came after that. The time average of the interviews was 30 minutes for the audio recordings and about 500 words for the written answers. The purpose was to accomplish a complementarity in the investigation about the perceptions and reasons of preferences of social networks and new media technology as a substantial variable in relieving the Rohingya crisis. The interviewees were two key persons in the British Rohingya Community in Bradford conducted face to face, three activists in the public work inside Rohingya camps in Bangladesh conducted via mobile telecommunication apps and Facebook messenger, and three experts in the Rohingya case via electronic mail, face to face, and WhatsApp audio communication.

\footnotetext{
1- https://www.bradford.gov.uk/your-community/asylum-seekers-and-refugees/bradfords-response-to-the-syrian-refugee-crisis/
} 
A semi-structured interview consists of seven questions about the possibilities of new media technology utilization including the different social networks and mobile apps in relieving humanitarian crisis of the Rohingya and how to overcome the prospect limitations. Moreover, to investigate the reasons that make some respondents disagree that media technology can play a positive role in relieving their crisis.

The interviews that conducted after analyzing questionnaire findings include questions about some unexplained facts such as the reasons that make Facebook the most popular social media platform among Rohingya refugees and why majority of them indicated their disagreement that Twitter and YouTube are insufficient media platforms to play a positive role in relieving their humanitarian crisis. Moreover, the Rohingya consider spreading awareness about their issue worldwide is the most substantial function that new media technologies can accomplish rather than any other possible functions. Furthermore, it was essential to evaluate the organizational involvement in the crisis and whether it offers the Rohingya refugees communicational services that optimize their community resilience and mitigate the traumatic consequences of the crisis or there are practical proposals can be suggested in this context.

\section{Findings}

This section consists of three parts, the first part is the questionnaire descriptive and analytical results, the second is the interview outcomes, and the third is the triangular analysis that concludes the whole investigation that interprets the three objectives of the study together. the descriptive and analytical results of the questionnaire investigate mainly the first objective of the research that explores the perceptions and convictions of the Rohingya about using mobile apps and social media to relieve their crisis, however, the interview outcomes focus on the suggestions and the limitation that obstruct the use of the new media technologies.

\subsection{General Descriptive Analysis}

The respondents are 57\% males and $43 \%$ females. Most of the sample are young people as students (20-30) years old represents $47.7 \%$, and the category between $(31-50)$ is $39.2 \%$, and the oldest category that aged above 50 is $13.1 \%$.

The respondents that have occupation as employers are $(22.3 \%)$ and those who described themselves as "activists" are (17\%). Unexpectedly, the largest category after student are the unemployed citizens either as housewives or as non-working persons (30\%). This fact can be reasonable regarding that most of the Rohingya families when they came to the UK, they had young children and not skilled in speaking English. Even though, after years of attending regular schools, the children will join the universities and would have a permission to work in permanent jobs. Some of the parents are working now privately as taxi drivers.

However, the permanent residency of the Rohingya people is in Bangladesh or in Myanmar, $(82 \%)$ consider UK as their place of residency and (9\%) indicate Bangladesh and (6\%) report Myanmar. (3.8\%) confirms Pakistan and India as their place of residency. The Rohingyan people in Bradford is generally heavy user of media, (40\%) spend more than 4 hours daily in watching TV or interacting with social media networks, (38.5\%) spend 2-4 hours daily, and (21.5\%) spend less than two hours daily. (Table 1) 
Table 1

\begin{tabular}{|c|c|c|c|}
\hline \multirow{4}{*}{ Gender } & Attributes & Frequencies & Percentage \\
\cline { 2 - 4 } & Male & 74 & $56.9 \%$ \\
\cline { 2 - 4 } & Female & 56 & $43.1 \%$ \\
\cline { 2 - 4 } Age & Total & 130 & $100 \%$ \\
\hline & $20-30$ & 62 & $47.7 \%$ \\
\cline { 2 - 4 } & $31-50$ & 51 & $39.2 \%$ \\
\cline { 2 - 4 } & Over 50 & 17 & $13.1 \%$ \\
\hline \multirow{4}{*}{ Occupation } & Total & 130 & $100 \%$ \\
\cline { 2 - 4 } & Student & 45 & $34.6 \%$ \\
\cline { 2 - 4 } & Employee & 29 & $22.3 \%$ \\
\cline { 2 - 4 } & Activist & 17 & $13.1 \%$ \\
\cline { 2 - 4 } & None & 39 & $30 \%$ \\
\hline \multirow{4}{*}{ Tesidency } & Total & 130 & $100 \%$ \\
\cline { 2 - 4 } & Bangladesh & 107 & $82.3 \%$ \\
\cline { 2 - 4 } & Myanmar & 12 & $9.2 \%$ \\
\cline { 2 - 4 } & Other countries & 6 & $4.6 \%$ \\
\cline { 2 - 4 } & Total & 130 & $3.8 \%$ \\
\hline \multirow{4}{*}{ Duration } & Less than $2 \mathrm{H}$ & 28 & $21.5 \%$ \\
\cline { 2 - 4 } & 2-4 Hours & 50 & $38.5 \%$ \\
\cline { 2 - 4 } & More than $4 \mathrm{H}$ & 52 & $40 \%$ \\
\cline { 2 - 4 } & Total & 130 & $100 \%$ \\
\hline & & & \\
\hline \multirow{4}{*}{} & & 5 & $100 \%$ \\
\hline
\end{tabular}

\subsection{Rohingya preferences for media platforms}

Facebook comes at the first rank as the most used social network among respondents (43.8\%), an authorized source emphasizes this result also among Rohigya in Bangladesh and Myanmar, saying that Facebook is the dominant media network because it can be uploaded faster than any other social media platform and it provides a rich medium of connectivity and multiple level of audio-visual communication between family members, neighbors, and friends who have moved away from one another as a result of their humanitarian crisis.

Regarding the high rate of low-educated and unemployed people in the Rohingya population in Bradford, about $(40.8 \%)$ indicated that watching TV comes in the second rank after Facebook. In the third rank, the respondents reported YouTube (41.5\%) followed by Twitter in the fourth position (41.5\%). Radio and newspapers are the lowest ranking, Radio is in the fifth level as a media option and the newspapers is in the sixth and last position.

\subsubsection{Mobile Apps}

Only $29.2 \%$ of the respondents believe that mobile apps could be useful in relieving their crisis, however, $33.8 \%$ disagree and $37 \%$ have no idea about the possibilities of using mobile apps in rescue operations or supporting people in devastated areas. Those who agree that using mobile apps is beneficial, pointed out the ability of using it for communication purposes and providing connectivity advantages with family members and rescue workers when the crisis strikes. UNHCR Emergency Handbook app and UNHCR Refugee Site Planning are the most popular with average $(54.6 \%)$ and $(13.8 \%)$ respectively.

\subsubsection{YouTube}

It seems that there is a probable correlation between watching YouTube channels and the conviction that it could be an effective platform in relieving the Rohingyan crisis. The respondents agree $(54.6 \%)$ that YouTube videos can create global awareness about their issue (51\%), demonstrating the real tragedy of the Rohingya people (22\%), Following the news reports and the urgent events $(16.2 \%)$, spreading understanding and peace among world nations (15.4\%), and coordinating relief work to help affected victims. (Table 5) The most viewed YouTube channel by respondents is the "Rohingya Vision TV" $(35.4 \%)$ and the second channel is the BBC World News (13.1\%) followed by the CNN World News (8.5\%). The respondents mentioned some other channels that was not listed in the questionnaire such as, Al Jazeera, Skynews, and Rohingya Mukar TV (7.7\%).

4.2.3 Facebook

The respondents agree that Facebook can be employed to interact positively with their issue regionally and globally in many ways $(52.3 \%)$. They are convicted that Facebook can create global awareness about their political and humanitarian crisis $(46.2 \%)$ through reporting the real story of their historical citizenship denial (30.8\%), and could be a convenient medium to be informed about the latest news and current events (21\%). Furthermore, the Facebook proved its efficacy as a medium to share interest with celebrities and influential figures in different specialties that can employ their networks to spread the word and support Rohingya appeals and petitions. 
Moreover, the respondents added Facebook as a strong tool to improve wellbeing and feeling of dignity and sense of belonging. Also, they indicated the importance of Facebook in coordinating relief work $(10 \%)$ and spreading values of understanding and peace among world nations (9\%). The most visited pages are, Rohingya Vision (25\%) the second page is the British Rohingya Community $(12.3 \%)$, which make sense as they use it to keep in touch with their local community in Bradford. Other pages were limitedly selected to engage with the Rohingyan issue such as, "Friends who like Burma, Rohingya News Myanmar" (7.7\%) and "Rohingya of Myanmar" (6.2\%). These questions were multiple choice.

4.2.4 Twitter

The conviction that twitter can be beneficial in relieving humanitarian crisis between respondents is relatively high (50\%) especially in highlighting the Rohingya crisis and increase global awareness about the facts of this historical political conflict (32\%).

There is an agreement that twitter can be useful in activating and circulating supporting hashtags about the human rights of Rohingya in their homeland and in living freely, respectfully, and enjoying equality, identity, and dignity. (24.6\%) Moreover, respondents think that Twitter is beneficial in providing up-to-date knowledge and information about world news and events and about their own first interest of the Rohingya issue (15.4\%). The most popular twitter account is @EU Rohingya Council as it keeps them in touch with the most recent news and political decisions that may directly influence their existence in a European country (26.9\%). (Table 2) These questions were multiple choice.

Table 2

\begin{tabular}{|c|c|c|c|c|c|}
\hline Twitter Accounts & Frequencies & Percentage & Twitter Accounts & Frequencies & Percentage \\
\hline a.Rohingya & 5 & $3.8 \%$ & @,Protect the Rohingya & 4 & $3.1 \%$ \\
\hline a)Rohingya Crisis & 5 & $3.8 \%$ & a,EU Rohingya Council & 35 & $26.9 \%$ \\
\hline a,Rohingyas & 5 & $3.8 \%$ & a)Report Rohingya & 7 & 5.45 \\
\hline (a)Op Rohingya & 3 & $2.3 \%$ & (a)RohingyaMuslims & 6 & $4.6 \%$ \\
\hline (a)Rohingya Blogger & 5 & $3.8 \%$ & a)Rohingya Peace & 4 & $3.1 \%$ \\
\hline @VoiceRohingya & 3 & $2.3 \%$ & @,AllRohingyaNow & 3 & $2.3 \%$ \\
\hline Other Accounts & 3 & $2.3 \%$ & & & \\
\hline
\end{tabular}

\subsection{Significant Correlation Analysis}

Two main correlations have been investigated to detect the possible significance between variables relationships. The independent variables are the demographic attributes including gender, age, occupation, media usage, and residency. The dependent variables encompass the respondents' potential perceptions of using media technologies such as social media platforms and mobile apps. Also, the dependent variables contain the probable tendency to order these platforms within a certain ranking system includes TV, Radio, and newspapers as traditional media. Chi-Square test is used to diagnose relations with equal proportions. $(\mathrm{a} \leq 0.05)$

1- $\quad$ No significant correlation has been found between gender and considering any of the media technologies or social networks beneficial in relieving the Rohingya crisis. However, A significant relationship has been detected between age and agreeing that mobile apps $(, 00)$, YouTube $(, 00)$, Twitter $(, 00)$, and Facebook $(, 00)$ can provide real opportunities to solve Rohingya problems and facilitate their lives. There is an evidence that young people (20-30 years old) has more tendency to believe in the efficiency of utilizing these media accompanied by a higher likelihood to employ it more than the older ages. Another one emerged between the type of occupation and the conviction that mobile apps $(, 00)$, Facebook $(, 00)$, YouTube $(, 00)$, Twitter $(, 00)$ are beneficial in supporting their demands and ensure their human rights. We can notice that students tend to highly evaluate employing and activating these media platforms. However, the unemployed citizens tend to disagree with this point of view. 


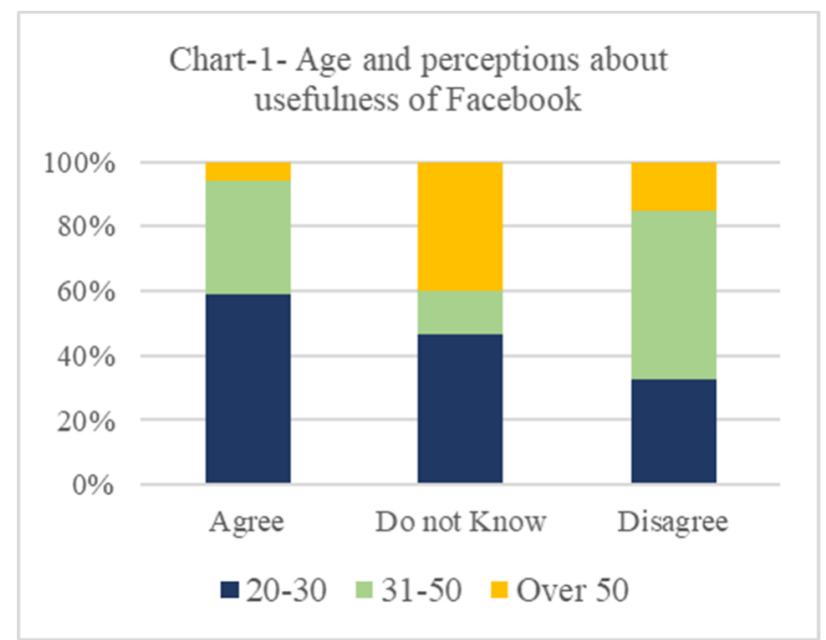

2- $\quad$ There is an evidence that the place of residency correlates significantly with the perceptions about usefulness of mobile apps (.04), YouTube (.05), and Facebook (.03), however the correlation with Twitter seems to be insignificant.

3- $\quad$ The daily average of media consumption has a significant relationship only with Facebook as a social media platform (.00). However, no evidence that it has correlation with any other social network or mobile app. Age of Rohingya participants correlates significantly with their media preferences. A significant relationship seems to exist between age and TV (.00), Facebook (.00), Twitter (.03), and Radio (.00). However, there is no relation seems to be significant between age and either YouTube or newspapers.

4- The current occupation of Rohingya is significantly correlated with media platforms preferences. Media platforms such as Facebook (.03), TV (.00), Twitter (.00), and Radio (.01) seem to have relationship with Rohingya profession except newspapers and YouTube.

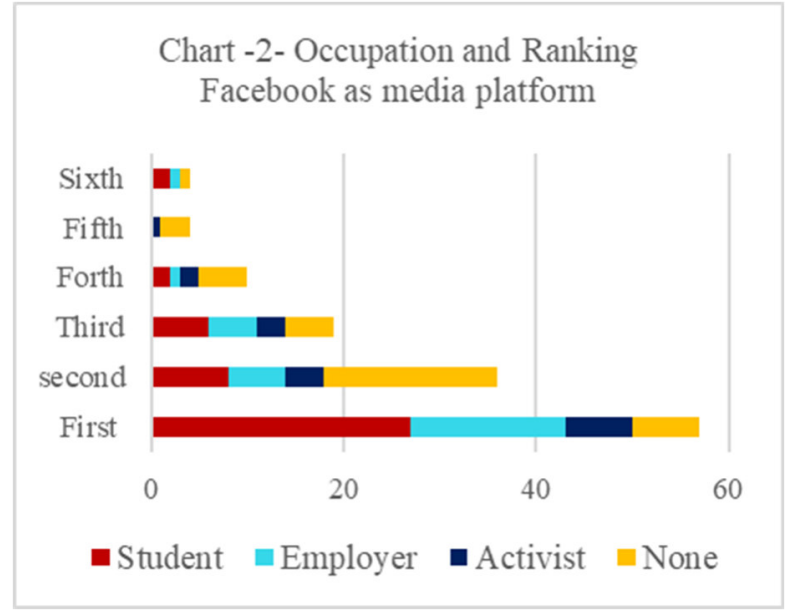

5- It seems that there is no evidence supports the relation between the Rohingya place of residency and their media platform preferences. However, there are two exceptions, the relationship between place of residency and the ranking of YouTube (.00) and newspapers (.00)

6- $\quad$ A significant correlation has been found between Rohingya average of media consumption and their preferences for TV (.03), Twitter (.00), and Radio (.03). However, no significant correlation seems to link between average of media consumption and YouTube, Facebook, and newspapers. 


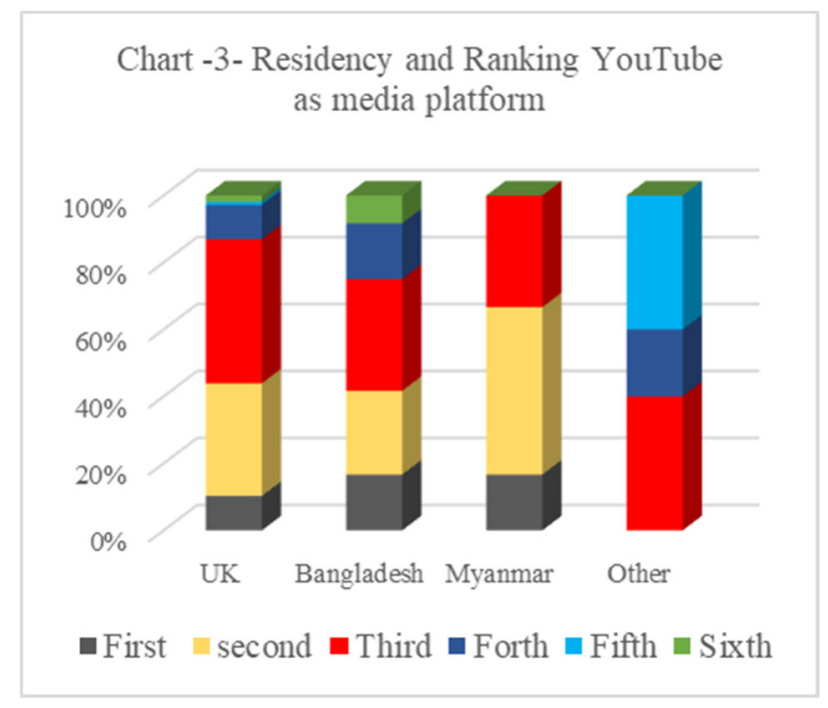

\subsection{New Media Technologies and Rohingyan Crisis}

Interviews with experts in the Rohingyas affairs and with Rohingya activists on social media were beneficial in complementing the epistemological framework that represents the principal interest of investigating the potential new media technologies possibilities and limitations in relieving the humanitarian crisis of the Rohingya. The variety of the interview sources that include activists from inside Bangladesh camps, activists in the international institutions, academics and professionals specialized in the Rohingya affairs and the media, was essential to integrate information about Rohingya issue and achieve a considerable level of inclusiveness in exploring areas of investigation and explaining the relationships significance within the analytical quantitative part of the study.

As many studies have shown, the media can play a significant role in relieving not only the humanitarian crisis of the Rohingyan people, but also all the humanitarian crises of the persecuted minorities around the world (Wade, F. 2017, Abbasi, M. A. 2017, Ahmed, A. 2011, Al., K.B.E. 2011, Davis, A. 2017, Howe, A.W. et al. 2011, Kramer, T. 2015, Mann, R. D.2016, Rochmawati N.\& Wibawas, C.2018). There are three main aspects should be considered in the desired role of the media in addressing the humanitarian crisis as defined by one of the professional interviewees. ${ }^{(1)}$ First, the role of the media in advocating the humanitarian work, sharing information, reporting facts, and operating as an assistant party to coordinate the relieving response. Second, the advocating role of the media to drive political decisions supporting the humanitarian work. Powerful media campaigns can profoundly foster all rescue, relief, and support operations. Third, the communicative role of the afflicted people themselves to access world news portals and deliver their testimonies from the ground. The role of the people is essential to report the inaccessible news by the media and to provide their own vision about the potential risks and possible solutions of their issue.

The crisis of the mass exodus of the Rohingyan people started in 2012. More than 200,000 persons mostly females, young children, and the elderly left their homes, lands, and villages to escape from the Burmese Military brutality and persecution. The well-known international media like BBC and CNN were completely absent away from the scene ${ }^{(2)}$. When the Rohingyan settled down in Bangladesh refugees' camps after their second exodus wave from Arakhan State in August 2017, several media channels and networks start to cover their stories and report their news such as Aljazeera, Sky news, BBC, CNN. The problem is that news reports in this stage of the crisis do not clarify the historical roots of the conflict which constitutes the original reasons behind the humanitarian crisis of the Rohingya. The portrayals of the crisis are drawn up by the media outside its sociopolitical context and focus on the dramatic conditions of the afflicted people within different frames of loss, misery, and helplessness. These news frames may drive empathy and support but without real clarification of the historical and political background of the crisis which could produce practical steps to solve the problem by sharing awareness and mobilize the world public opinion to stand for the human rights and justice.

The employment of mobile apps in the Rohingya humanitarian crisis as a geo-positioning utility seems to be not effective for many reasons. First, because of the nature of the crisis itself that does not require the geopositioning technology to accelerate rescue operations by detecting the trapped people in the affected areas. Alternatively, the mass exodus of the Rohingyan people has occurred in an open and clear movement from Arakhan state to Bangladesh. Nevertheless, the mobile phones applications are used inside the refugee camps as a

\footnotetext{
1 - An Interview with an expert in the Rohingya affairs and consultant in Emergency Medicine, Trustee of Doctors Worldwide, Special Interest in International Emergency Medicine, Humanitarian Relief, and Disaster Response. at 12-04-2018.

2 - An Interview with a key person of the BRC in Bradford at 14-04-2018.
} 
medium to contact remote medical service. "Tele-Medicine" ${ }^{(1)}$ is one of the remote medical consulting services that can offer diseases diagnose and prescription for the patients in the refugee camps that suffer from healthcare severe shortage after collecting the "good enough" visual, audio, and documented information about the case. ${ }^{(2)}$

\subsection{Social networks and Rhingyan Crisis}

The media performance in covering the Rohingya humanitarian crisis constituted an important lesson to the Rohingyan people who learnt that no one will speak on behalf of them and they should not wait or expect any external media coverage, rather they should employ every possible means to report their news and reveal the facts to the world ${ }^{(3)}$. Imo and WhatsApp mobile audiovisual communication applications were employed to secretly document persecution and violence incidents committed by Buddhists extremists and Burmese military troops. The video clips of the killing, raping, and burning alive accidents circulated the mobile apps and then transmitted to the Facebook and YouTube.

Facebook is the most social network used by Rohingya people to communicate and interact about their issue. They use their personal accounts, especially the young generation, to spread awareness about their plight and counter the Burmese authorities' accusations that claim that Rohingya are terrorists and aggressors. YouTube is not commonly used as it needs a strong network sign to operate. The Rohingya in Bangladesh are not communicatively empowered enough to access strong network sign. Therefore, it is much easier for them to upload their media materials via Facebook or via WhatsApp that can be operated with minimum availability of internet network sign.

Using Twitter is limited to activating hashtags that mobilize support for relieving the Rohingya crisis or to grab the international public opinion attention to the issue. Lately, The Rohingyan people just realized the significance role of Twitter in supporting their cause. This was not the case three years ago. ${ }^{(4)}$

\subsection{Restrictions of employing New Media Tech in the Crisis}

More than one reason makes the utilization of social media in humanitarian crisis like the Rohingya case fraught with difficulties, obstacles, and even risks. The complicated political situation of the Rohingya as a minority devastates many of their campaigns expected impact and undermines their efforts to spread awareness about their issue. The Burmese government has massively recruited social media bots to encounter the Rohingya hashtags that aim to clarify the situation or address the issue from their point of view. the oppositional social media accounts report the Rohingyas activists' pages to the Facebook administration to block it or close it permanently. ${ }^{(5)}$

The stateless case of the Rohingya people and depriving them from national identity by unreasonable citizenship denial which constitutes a crime against humanity, complicate their right to access telecommunication services legally in Bangladesh. The fact that enforces Rohingya to illegally own SIM cards to keep in touch with the world. One of the suggestions to solve this problem is that the involved organizations adopt an initiative to produce "Unlimited ID" SIM cards for the Rohingya to legalize communications and strengthen the capacities of uploading materials that represent proofs and evidences that support their issue and demonstrate the real stories behind news to media platforms and social networks ${ }^{(6)}$.

When organ0izations responding to any humanitarian crisis they send a committee to evaluate the whole situation and produce a comprehensive report about the urgent needs of the afflicted people including shelter, food, healthcare, security, etc., but they fail to take into consideration the communication needs, which may not be less important than other needs, but may exceed them because they help in shaping public opinion and consequently the political decision-making, which may contribute to the solution of the crisis. ${ }^{(7)}$

\section{Conclusions}

There are two main inductions should be highlighted when approaching the conclusions part of this research. First, it is essential to demonstrate the Rohingyas point of view and perceptions about the functionality of social media platforms and mobile apps in relieving their humanitarian crisis. This would explain the reasons behind the worldwide ignorance of their issue which the Rohingyas themselves could be responsible for. Moreover, it would suggest applicable steps can be taken to optimize the functionality of media platforms before, during, and after the crisis especially if probabilities of fueling the same political conflict that produces similar or worst humanitarian crisis is quite expected in other countries ${ }^{(8)}$.

Secondly, it is substantial to investigate the extent to which the emergency and crisis communication models

\footnotetext{
1 - The remote diagnosis and treatment of patients by means of telecommunications technology.

2 - Expert in Rohingya affairs, Ibid.

3 - Key person in BRC, Ibid.

4 - Interview with a Rohingyan activist in Bangladesh at 05-07-2018

5 - BRC key person, Ibid.

6 - Interview with Rohingyan social media activist in Bangladesh camps.

7 - Expert in Rohingyan affairs, Ibid.

8 - https://thewire.in/communalism/toxic-myths-about-muslims-are-fueling-indias-road-to-ruin
} 
could be sufficient to interact with the Rohingya issue at the short- term media strategy during the crisis. In addition to an examination of the social information processing (SIP) assumptions that computer-mediated communication provides unlimited opportunities for connectivity and that online communicator are incentivized to portray favorable images of themselves to social media users. The SIP, if possible, could maintain a long-term communication strategy that support society cohesion, eliminate hate speech, and avoid divisiveness that may lead to explosive humanitarian crises such as ethnic cleaning or genocide.

It seems that Facebook is the preferred social network for Rohingya refugees for its perceived easiness to communicate internally with community members and externally with international identities. Facebook's success in reuniting families that have lost some of its members as a result of the crisis proved its efficacy as a social media platform and increased its popularity more than any other social media platform. Rohingya perceived Twitter as a network for high educated and famous people, not for majority of them. Some Rohingya activists launched supportive hashtags and ask celebrities to share and retweet it to benefit from their fame. Using YouTube is very limited to watch Rohingya Vision news channel. Almost all videos about Rohingya crisis have been produced by external media channels or agencies and reflect its editorial policies. Most of the Rohingya use smart phones, but they have limited knowledge about its advanced functions. IMO and WhatsApp are the preferred audio-visual applications for different communication purposes. Nevertheless, they have very restricted knowledge about the multiple mobile apps produced by UN and NGOs to facilitate their life and provide guidelines to access necessary services in times of risks and crises.

Traditional Emergency Communication Models are simply inapplicable regarding the Rohingya humanitarian crisis. It can be considered only on the after crisis stage when the people leave their lands and flee to neighbor places because of the military authorities that prohibit all media forms inside Arakhan state and no possibility to activate any communication strategy before or during the crisis.

Long-term communication strategy aims to maintain social cohesion and eliminate hate speech in Myanmar is crucial to preserve community unification. Despite its ideality as a media policy, it constitutes the real guarantee to avoid weaponizing social media that may produce an explosive humanitarian crisis. Computer mediated communication of any type should be offered and developed by the government as an essential infrastructural service. The discovered information about Rohingya plight has been processed through social media in an exceptional context and granted the Rohingya refugees worldwide a unique opportunity to connect with wider societies. The Rohingya Refugees reinvented their national identities to present themselves with preferred images and characters on Facebook pages, Twitter accounts, and YouTube channels. The previous two points ensure the validity of the social information processing assumptions regarding the unprecedented opportunities of communication for Rohingyas and the possibilities to select preferred self-presentation that computer mediated communication offers for users.

The NGOs can offer Rohingya media literacy basic knowledge and news reporting and communication skills training courses that profoundly improve their capacities to utilize social media platforms and news networks. Simultaneously, this knowledge would prevent any prospect media misuse especially by enthusiastic Rohingya activists or even any armed or terrorist groups.

\section{Discussion}

Unexpectedly, the Rohingya crisis disclosed what was hidden for decades and granted the oppressed people unprecedented opportunity to express themselves, tell their stories, and openly explain the issue from their own point of view and spread awareness worldwide. Throughout the Rohingya presence in Arakhan state, they were forbidden from enjoying any of their basic human rights. Depriving from media and communication services was a systematic practice by the Myanmar military authorities. As a consequence of citizenship denial, they were not allowed to legally own SIM cards for communication purposes or to have the simplest form of media such as local newspaper or Radio station. (1) Rohingya mass exodus outside Myanmar escaping death or burning was an extraordinary chance to use telecommunication services and enable them to upload videos, pictures, news reports, and appeals that clarify the story and keep the world in touch with their issue. When the Rohingya exposed the brutal persecution that they are suffering from by Myanmar military gangs and Buddhists extremists on social media, the international news networks start to pay attention to their cause and send correspondents to report their news.

The Rohingyas crisis is not just a humanitarian plight, but it constitutes a complicated political and social issue with an extensive historical background. Any suggested communication plan should consider the specificities of this case. The ethnographical attributes, the geographical circumstances, and regional power balances are some of these specificities.

Some humanitarian crises are too complicated to be responsive to any short-term communication strategy designed mainly to operate within environmental, natural, industrial, or health disasters. In the Rohingya crisis,

\footnotetext{
${ }^{1}$ - An interview with a media scholar specialized in migrant affairs at 07/08/2018
} 
there was no way to document the brutal violations in addition to use media to mitigate its traumatic effects. The full mission/risk is on the victims' shoulders to prove the crimes and define perpetrators. The international media big silence before and during the mass killing acts was the first supporter of the criminals to proceed with their crimes.

To approach a communication model that explains the functionality of the social media platforms and traditional media performance in relieving the humanitarian crisis of the Rohingya, three aspects should be considered. First, the media governmental policy that believes in empowering people with media is better than depriving them of expressing themselves. Second, the NGOs can compensate the communication inadequate by providing communicative alternatives and facilitate accessing services in addition to its role to eliminate media illiteracy that may lead to media misuse. Finally, the Rohingya themselves should broaden their vision to the potential horizons of using social platforms and be aware of new media technologies possibilities and limitation that optimize the supportive functions to their cause.

\section{References}

Azizah, N. S., I; Kusumawati, A 2017. The Development Perceived of the Product Comments Trust-Ability on social Media: A Social Information Processing (SIP) Theory. Russian Journal of Agricultural and SocioEconomic Sciences, 62.

Abbasi, M.-A., Kumar, S., Andrade Filho, J. A. \& Liu, H. 2012. Lessons learned in using social media for disaster relief-ASU crisis response game. International Conference on Social Computing, Behavioral-Cultural Modeling, and Prediction. Springer, 282-289.

Abdul Bari, M. 2018. The Rohingya Crisis - A People Facing Extinction. Kube Publishing.

ABS-CBN 2017. Social media 'hate speech' aggravating Rohingya crisis: US official. ABS-CBN News, 22 Sep.

Aggergaard, S. P. 2015. Crisis communications and social media: the game just got tougher. The Computer \& Internet Lawyer.

Ahmed, A. 2011. "Use of Social Media in Disaster Management". ICIS Conference Proceedings. 16.

Ajao, T. \& Wielenga, C. 2017. Citizen Journalism and Conflict Transformation: The Ushahidi's Response to Kenya's 2008 Post-Election Violence. Matatu: Journal for African Culture \& Society, 49, 467-486.

Al., K. B. E. 2011. Crowdsourcing, citizen sensing and sensor web technologies for public and environmental health surveillance and crisis management: trends, OGC standards and application examples. International Journal of Health Geographics, 10.

Alberto Simoes, J. \& Campos, R. 2016. Youth, social movements and protest digital networks in a time of crisis. Juventude, movimentos sociais e redes digitais de protesto em época de crise., 13, 126-145.

Alencar, A. 2017. Refugee integration and social media: a local and experiential perspective. Information, Communication \& Society, 1-16.

An, S.-K. \& Gower, K. K. 2009. How do the news media frame crises? A content analysis of crisis news coverage. Public Relations Review, 35, 107-112.

Anbarasi, C. \& Mayilvahanan, P. 2017. Humanitarian assistance ontology implementation during disaster management in Chennai flood-2015 using text mining techniques. International Journal of Pure and Applied Mathematics, 116, 729-738.

Appling, S., Briscoe, E., Carpenter, A., Mccook, L., Scott, G., Allen, T., Buettner, R. \& Oros, C. 2015. Social Media for Situational Awareness: Joint-Interagency Field Experimentation. Procedia Engineering, 107, 319324.

Asmolov, G. 2015. Crowdsourcing and the folksonomy of emergency response: The construction of a mediated subject. Interactions: Studies in Communication \& Culture, 6, 155-178.

Awan, I. 2017. Cyber-Extremism: Isis and the Power of Social Media. Society, 54, 138-149.

Baron, G. \& Philbin, J. 2009. Social media in crisis communication: Start with a drill. Public Relations Tactics, $16,12-12$.

Baruh, L. 2015. Social media and citizen engagement in crises. Interactions: Studies in Communication \& Culture, 6, 131-139.

Bennett, S. 2018. New “Crises," Old Habits: Online Interdiscursivity and Intertextuality in UK Migration Policy Discourses. Journal of Immigrant \& Refugee Studies, 16, 140-160.

Bejuri, W.M., Mohamad, M.M., \& Radzi, R.Z. (2016). A Proposal of Emergency Rescue Location (ERL) using Optimization of Inertial Measurement Unit ( IMU ) based Pedestrian Simultaneously Localization and Mapping ( SLAM ).

Bonnet, E., Nikiema, A., Traore, Z., Sidbega, S. \& Ridde, V. 2017. Technological solutions for an effective health surveillance system for road traffic crashes in Burkina Faso. Global Health Action, 10, N.PAG-N.PAG

Bozdag, C. \& Smets, K. 2017. Understanding the Images of Alan Kurdi with "Small Data": A Qualitative, Comparative Analysis of Tweets About Refugees in Turkey and Flanders (Belgium).

Brandusescu, A. \& Sieber, R. E. 2018. The spatial knowledge politics of crisis mapping for community 
development. GeoJournal, 83, 509-524.

Brandusescu, A. \& Sieber, R. E. 2018. The spatial knowledge politics of crisis mapping for community development. GeoJournal, 83, 509-524.

Brandusescu, A. \& Sieber, R. E. 2018. The spatial knowledge politics of crisis mapping for community development. GeoJournal, 83, 509-524.

Brooten, L., Ashraf, S. I. \& Akinro, N. A. 2015. Traumatized victims and mutilated bodies: Human rights and the 'politics of immediation' in the Rohingya crisis of Burma/Myanmar. International Communication Gazette, 77, 717-734.

Burke, A. 2016. New political space, old tensions: History, identity, and violence in rakhine state, myanmar. Contemporary Southeast Asia, 38, 258-283.

Caraway, B. 2016. Crisis of Command: Theorizing Value in New Media. Communication Theory, 26, 64-81.

Carpenter, S. \& Lertbratchya, A. P. 2016. A Qualitative and Quantitative Study of Social Media Communicators: An Extension of Role Theory to Digital Media Workers. Journal of Broadcasting \& Electronic Media, 60, 448-464.

Castillo, C. 2016. Big Crisis Data: Social Media in Disasters and Time-Critical Situations, Cambridge, Cambridge Univ Press.

Chung, S. \& Lee, S. 2016. Crisis Communication Strategy on Social Media and the Public's Cognitive and Affective Responses: A Case of Foster Farms Salmonella Outbreak. Communication Research Reports, 33, 341-348.

Clawson, R. A., \& Oxley, Z. M. (2013). Public opinion: Democratic ideals, democratic practice (2nd ed.). London; Los Angeles, Calif; SAGE/CQ Press.

Cottle, S. 2014. Rethinking media and disasters in a global age: What's changed and why it matters. Media, War \& Conflict, 7, 3-22.

Crijns, H., Cauberghe, V., Hudders, L. \& Claeys, A. S. 2017. How to deal with online consumer comments during a crisis? The impact of personalized organizational responses on organizational reputation. Computers in Human Behavior, 75, 619-631.

Creswell, J. W. \& Clark, V. L. P. 2007. Designing and conducting mixed methods research.

Creswell, J. W. 2011. Research Design, qualitative and quantitative, and mixed methods approaches. Sage publications.

Culbertson, H. M. 2014. Citizen journalism: Valuable, useless or dangerous? Journalism and Mass Communication Quarterly, 91, 190-192.

D., S. D. M. 2017. The Othering of Muslims: Discourses of Radicalization in the New York Times, 1969-2014. Sociological Forum, 32, 138-161.

Davies, K., 18(1): 69-82. 2012. Safety vs credibility: West Papua Media and the challenge of protecting sources in dangerous places. Pacific Journalism Review, 18, 69-82.

Davis, A. 2017. How Social Media Spurred Violence Against Rohingya in Myanmar. News Deeply, 14 Sep.

De Albuquerque, J. P., Herfort, B., Brenning, A. \& Zipf, A. 2015. A geographic approach for combining social media and authoritative data towards identifying useful information for disaster management. International Journal of Geographical Information Science, 29, 667-689.

Dickinson, E. 2009. Neighborhood watch. Foreign Policy, 170.

D. Kamissoko, P. Z., F. Peres 2014. Decision process in large-scale crisis management. Environment Systems and Decisions, 34, 277.

Domdouzis, K., Akhgar, B., Andrews, S., Gibson, H. \& Hirsch, L. 2016. A social media and crowdsourcing data mining system for crime prevention during and post-crisis situations. Journal of Systems and Information Technology, 18, 364-382.

Donnelly, J. 2003. Universal Human Rights in theory and practice. second edition, Cornell University.

Donnelly, J. A. W., D 2017. International Human Rights. Avalon Publishing.

Doucet, L. 2018. Syria \& the CNN Effect: What Role Does the Media Play in Policymaking? Doedalus, 147, 141157.

Downs, R. M. (2014). Coming of age in the geospatial revolution: The geographic self-re-defined. Human Development, 57, 35-57.

Doyle, E. \& Lee, Y. 2016. Context, context, context: Priming theory and attitudes towards corporations in social media. Public Relations Review, 42, 913-919.

Duberry, J. 2016. Environmental governance in the internet age - the impact of new information and communication technologies. Environmental Policy and Law, 46, 222-227.

Elgharmy, K. 2015. Periphery Discourse: An Alternative Media Eye on the Geographical, Social and Media Peripheries in Egypt's Spring. Mediterranean Politics, 20, 255-272.

Falcioni, J. G. 2010. HELPING PEOPLE HELP THEMSELVES. Mechanical Engineering, 132, 6.

Falcioni, J. G. 2011. Project: Crowdsourcing. Mechanical Engineering, 133, 25. 
Ferre, J., P. 2015. Media framing of the muslim world: Conflicts, crises, and contexts. Journalism and Mass Communication Quarterly, 92, 516-518.

Fine, G. A. \& White, R. D. 2002. Creating Collective Attention in the Public Domain: Human Interest Narratives and the Rescue of Floyd Collins. Social Forces, 81, 57-85.

Freifeld CC, C. R., Mekaru SR, Chan Eh, Kass-Hout T, Ayala Iacucci A, Et Al 2010. Participatory Epidemiology: Use of Mobile Phones for Community-Based Health Reporting. PLoS Med, 7, e1000376.

Gaspar, R., Pedro, C., Panagiotopoulos, P. \& Seibt, B. 2016. Beyond positive or negative: Qualitative sentiment analysis of social media reactions to unexpected stressful events. Computers in Human Behavior, 56, 179191.

Glynn, C. J. (2016). Public opinion (Third ed.). Boulder, CO: Westview Press, A Member of the Perseus Books Group.

Guidry, J. P. D. A., Lucinda L.; Carlyle, Kellie E.; Et Al. 2018. Welcome or Not: Comparing \#Refugee Posts on Instagram and Pinterest. American Behavioural Scientist, 62, 512-531

Guidotti, T. L. 2013. Communication Models in Environmental Health. Journal of Health Communication. 18 (10): 1166-1179.

Gutworth, M. B., Cushenbery, L. \& Hunter, S. T. 2016. Creativity for Deliberate Harm: Malevolent Creativity and Social Information Processing Theory. The Journal of Creative Behavior, n/a-n/a.

Hagen, L., Keller, T., Neely, S., Depaula, N. \& Robert-Cooperman, C. 2017. Crisis Communications in the Age of Social Media: A Network Analysis of Zika-Related Tweets. Social Science Computer Review, 0894439317721985

Hayden, J. R., 88(1), 199-201 2011. Cognitive surplus: Creativity and generosity in a connected age. Journalism and Mass Communication Quarterly, 88, 199-201.

Heinemann, D. S. 2011. Using You've Got Mail to Teach Social Information Processing Theory and Hyperpersonal Perspective in Online Interactions. Communication Teacher, 25, 183-188.

Houston, J. B., HAWTHORNE, J., PERREAUlT, M. F., PARK, E. H., GOLDSTEIN Hode, M., Halliwell, M. R., Turner Mcgowen, S. E., Davis, R., Vaid, S. \& Mc elderry, J. A. 2015. Social media and disasters: a functional framework for social media use in disaster planning, response, and research. Disasters, 39, 1-22.

Howe, A. W., Jennex, M. E., Bressler, G. H. \& Frost, E. 2011. Exercise 24: Using social media for crisis response. International Journal of Information Systems for Crisis Response and Management (IJISCRAM), 3, 36-54.

Ibrahim, A. (2016). The Rohingyas: inside Myanmar's hidden genocide. Hurst \& Company, London

Jahng, M. R. \& Hong, S. 2017. How Should You Tweet? The Effect of Crisis Response Voices, Strategy, and Prior Brand Attitude in Social Media Crisis Communication. Corporate Reputation Review, 20, 147-157.

Jansen, S. C. 2002. Media in Crises: Gender and Terror, September 2001. Feminist Media Studies, 2, 139-141.

Jendrissek, D. 2016. Building a Future in Times of Crisis. Young, Highly Qualified Migrants in the UK. Journal of Contemporary European Studies, 24, 323-340.

Jiang, L, Bazarova, N, \& Hancock, J 2011, 'The Disclosure-Intimacy Link in Computer-Mediated Communication: An Attributional Extension of the Hyperpersonal Model', Human Communication Research, 37, 1, pp. 58-77, Communication \& Mass Media Complete, EBSCOhost, viewed 6 August 2018.

John, C. 1997. Development in Practice, 7, 203-204.

Jong, W. \& Duckers, M. L. A. 2016. Self-correcting mechanisms and echo-effects in social media: An analysis of the "Gunman in the Newsroom" crisis. Computers in Human Behaviour, 59, 334-341.

Kaewkitipong, L., Chen, C. C. \& Ractham, P. 2016. A community-based approach to sharing knowledge before, during, and after crisis events: A case study from Thailand. Computers in Human Behavior, 54, 653-666.

Karathanasi, K., Malliarou, M., Iliadi, I., Kaimaki, V. \& Prezerakos, P. 2014. Crowdsourcing disasters: Shifting Power to People. Balkan Military Medical Review, 17, 175-175.

Kase, S. E., Bowman, E. K., AL Amin, T. \& Abdelzaher, T. 2014. Exploiting social media for army operations: Syrian civil war use case. Army Research Lab Aberdeen Proving Ground MD Computational and information Sciences Directorate.

Kavanaugh, A. L., Sheetz, S. D., Sandoval-Almazan, R., Tedesco, J. C. \& Fox, E. A. 2016. Media use during conflicts: Information seeking and political efficacy during the 2012 Mexican elections. Government Information Quarterly, 33, 595-602.

Kawoosa, V.M. 2015. What are challenges of conflict reporting? https://www.quora.com/What-are-thechallenges-of-conflict-reporting

Khaldarova, I. \& Pantti, M. 2016. Fake News. Journalism Practice, 10, 891-901.

Killekar, O., Shah, H., \& Kolge, A. 2013. Social media metrics, tools \& analytics. Prima, 3, 35-47.

Kimmerle, J., Moskaliuk, J., Oeberst, A. \& Cress, U. 2015. Learning and Collective Knowledge Construction with Social Media: A Process-Oriented Perspective. Educational Psychologist, 50, 120-137.

Kramer, T. 2015. Ethnic conflict and lands rights in Myanmar. Social Research, 82, 355-374.

Lai, L. S. L. S. I. E. M. \& TO, W. M. W. I. E. M. 2015. CONTENT ANALYSIS OF SOCIAL MEDIA: A 
GROUNDED THEORY APPROACH. Journal of Electronic Commerce Research, 16, 138-152.

Leadbeater, M. N. "West Papua": Conflict in West Papua: The contrast between historic and contemporary media coverage in New Zealand". Pacific Journalism Review, 21, 230-240.

Li, J., Fraser, M. W. \& Wike, T. L. 2013. Promoting social competence and preventing childhood aggression: A framework for applying social information processing theory in intervention research. Aggression and Violent Behavior, 18, 357-364.

Liu, S. B. \& Palen, L. 2010. The New Cartographers: Crisis Map Mashups and the Emergence of Neogeographic Practice. Cartography and Geographic Information Science, 37, 69-90.

Lyu, J. C. 2012. How young Chinese depend on the media during public health crises? A comparative perspective. Public Relations Review, 38, 799-806.

Mann, R. D. 2016. Media framing and the myth of religious violence: The othering of sikhs in The Times of India. Sikh Formations, 12, 120-141.

Meis, M. 2016. When is a conflict a crisis? On the aesthetics of the Syrian civil war in a social media context. Media, War \& Conflict, 10, 69-86.

Merchant, R. M., M.D., Elmer, S., M.A., \& Lurie, Nicole, M.D., M.S.P.H. 2011. Integrating social media into emergency-preparedness efforts. The New England Journal of Medicine, 365, 289-291.

Mesmar, S., Talhouk, R., Akik, C., Olivier, P., Elhajj, I. H., Elbassuoni, S., Ghattas, H. 2016. The impact of digital technology on health of populations affected by humanitarian crises: Recent innovations and current gaps. Journal of Public Health Policy, 37, 167-200.

Moeller, S. D. 2002. Locating Accountability: The Media and Peacekeeping. Journal of International Affairs, 55, 369-390.

Moran Yarchi \& Tal Samuel-Azran (2018) Women politicians are more engaging: male versus female politicians' ability to generate users' engagement on social media during an election campaign, Information, Communication \& Society, 21:7, 978-995, DOI: 10.1080/1369118X.2018.1439985

Moyo, L. 2015. Digital age as ethical maze: Citizen journalism ethics during crises in Zimbabwe and South Africa. African Journalism Studies, 36, 125-144.

Murillo, L. F. R. (2016). New expert eyes over fukushima: Open source responses to the 3/11 disaster in japan. Anthropological Quarterly, 89, 399-429.

Neubaum, G., Rosner, L., Rosenthal-Von Der Putten, A. M. \& Kramer, N. C. 2014. Psychosocial functions of social media usage in a disaster situation: A multi-methodological approach. Computers in Human Behavior, 34, 28-38.

Ngai, E. W. T., Moon, K. K., Lam, S. S., Chin, E. S. K., \& Tao, S. S. C. 2015. Social media models, technologies, and applications. Industrial Management \& Data Systems, 117, 769-802.

Ngai, E. W. T., Tao, S. S. C. \& Moon, K. K. L. 2015. Social media research: Theories, constructs, and conceptual frameworks. International Journal of Information Management, 35, 33-44.

Nicholson, B. B. N. M. A. U., Nugroho, Y. \& Rangaawamy, N. 2016. Social Media for Development: Outlining Debates, Theory, and Praxis. Information Technology for Development, 22, 357-363.

Nikunen, K. 2014. Hopes of hospitality: Media, refugee crisis and the politics of a place. International Journal of Cultural Studies, 19, 161-176.

Norbutas, L. \& Corten, R. 2018. Network structure and economic prosperity in municipalities: A large-scale test of social capital theory using social media data. Social Networks, 52, 120-134.

Norma, V.\& Arthur, V. 2018. Media coverage of the 'UK flooding crisis': a social panorama. Disasters, 42, 407431.

Norris, W. 2017. Digital Humanitarians: Citizen journalists on the virtual front line of natural and human-caused disasters. Journalism Practice, 11, 213-228. OECD Back to Work: Sweden, OECD Publishing.

Oh, O., Agrawal, M. \& Rao, H. R. 2013. Community Intelligence and Social Media Services: A Rumour Theoretic Analysis of Tweets During Social Crises. MIS Quarterly, 37, 407-A7.

Oh, O., Gupta, P., Agrawal, M. \& Raghav Rao, H. 2018. ICT mediated rumour beliefs and resulting user actions during a community crisis. Government Information Quarterly, 35, 243-258.

Paluck, E. L., Shafir, E. \& WU, S. J. 2017. Ignoring alarming news brings indifference: Learning about the world and the self. Cognition, 167, 160-171.

Patel, C., 2018. The Rohingyas: inside Myanmar's hidden genocide; Myanmar's enemy within Buddhist violence and the making of a Muslim 'other'. Oxford University Press.

Plenkovic, M. \& Mustic, D. 2011. Graphic technologies and communicational behaviour in ecological crises. Informatologia, 44, 296-308.

Poggiali, L. J. May 2017. Digital futures and analogue pasts? Citizenship and ethnicity in techno-utopian Kenya. The Journal of the International African Institute, 87, 253-277.

Provitolo, D., Dubos-Paillard, E., Verdiere, N., Lanza, V., Charriere, R., Bertelle, C. \& Aziz-Alaoui, M. A. 2015. Human behaviours in the face of disasters: From observing to conceptual and mathematical modelling. Cyber- 
Geo, 2015.

Puiglarrauri, H. K., A. 2013. Technology for Peacebuilding. International Journal of Security and Development, 2,61 .

Purohit, H., Hamton, A., BHATT, S., Shalin, V. L., Sheth, A. P. \& Flach, J. M. 2014. Identifying Seekers and Suppliers in Social Media Communities to Support Crisis Coordination. Computer Supported Cooperative Work: CSCW: An International Journal, 23, 513-545.

Ristovska, S. 2016. The rise of eyewitness video and its implications for human rights: Conceptual and methodological approaches. Journal of Human Rights, 15, 347-360.

Robinson, P. 2000. Research Note: The News Media and Intervention: Triggering the Use of Air Power During Humanitarian Crises. European Journal of Communication, 15, 405-414.

Rochmawati, N. \& Wibawa, S. C. 2018. Opinion Analysis on Rohingya using Twitter Data. IOP Conference Series Materials Science and Engineering, 336, 012013.

Rodriguez, C. M., Smith, T. L. \& Silvia, P. J. 2016. Multimethod prediction of physical parent-child aggression risk in expectant mothers and fathers with Social Information Processing theory. Child Abuse \& Neglect, 51, 106-119.

Ruffer, G. B. 2011. What Ushahidi can do to track displacement. Forced Migration Review, 1, 25-26.

Sandoval-Martin, T. \& Espiritusanto, Ó. 2016. Geolocation of information and data mapping with Ushahidi in online journalism. El profesional de la información, 25, 458-472.

Sandvik, K. B. \& Hoelscher, K. 2016. The Reframing of the War on Drugs as a "Humanitarian Crisis": Costs, Benefits, and Consequences. Latin American Perspectives, 44, 168-182.

Schwarz, A. 2012. How publics use social media to respond to blame games in crisis communication: The Love Parade tragedy in Duisburg 2010. Public Relations Review, 38, 430-437.

Segado-Boj, F., Diaz-Campo, J. \& Lloves-Sobrado, B. 2015. Latin American leaders on Twitter. Old uses for new media during political crises. Revista Latina de Comunicación Social, 156-173.

Shaheen, M. A. 2008. Use of social networks and information seeking behavior of students during political crises in Pakistan: A case study. International Information \& Library Review, 40, 142-147.

Silva, D. M. D. 2017. The Othering of Muslims: Discourses of Radicalization in the New York Times, 1969-2014. Sociological Forum, 32, 138-161.

Slagh, C. L. 2010. Managing chaos, 140 characters at a time: How the usage of social media in the 2010 Haiti crisis enhanced disaster relief, Georgetown University.

Spence, P. R., Sellnow-Richmond, D. D., Sellnow, T. L. \& Lachlan, K. A. 2016. Social media and corporate reputation during crises: the viability of video-sharing websites for providing counter-messages to traditional broadcast news. Journal of Applied Communication Research, 44, 199-215.

Springston, J. K., PHD., A.P.R., \& WEAVER-LARISCY 2007. Health crises and media relations: Relationship management-by-fire. Health Marketing Quarterly, 24.

Stanyer, J. (2013). Intimate politics: Publicity, privacy, and the personal lives of politicians in media-saturated democracies. Cambridge: Polity.

Steiner, H. E. 2007. international human rights in context: low, Politics, morals. third edition, Oxford Press.

Stephenson, J. M. 2005. Making humanitarian relief networks more effective: operational coordination, trust and sense making. Disasters, 29, 337-350.

Takahashi, B., Tandoc, E. C. \& Carmichael, C. 2015. Communicating on Twitter during a disaster: An analysis of tweets during Typhoon Haiyan in the Philippines. Computers in Human Behaviour, 50, 392-398.

Tapia, A. H., Bajpai, K., Jansen, B. J., Yen, J. \& Giles, L. Seeking the trustworthy tweet: Can microblogged data fit the information needs of disaster response and humanitarian relief organizations. Proceedings of the 8th International ISCRAM Conference, 2011. 1-10.

Tapia, A. H. \& Moore, K. 2014. Good Enough is Good Enough: Overcoming Disaster Response Organizations' Slow Social Media Data Adoption. Computer Supported Cooperative Work (CSCW), 23, 483-512.

Thigo, P. 2013. People, technology and spaces: towards a new generation of social movements. Journal of Contemporary African Studies, 31, 255-264.

Tully, M. 2015. Investigating the role of innovation attributes in the adoption, rejection, and discontinued use of open source software for development. Information Technologies \& International Development, 11, pp. 5569.

Turner, A. 2015. ANALYSIS: How social media is redefining crisis communications. Airline Business, 2-2.

UNCHR, 2017. Humanitarian Response Plan. September 2017- February 2018. Rohingya Refugee Crisis.

Van Lent, L. G. G., Sungur, H., Kunneman, F. A., Van De Velde, B. \& Das, E. 2017. Too far to care? measuring public attention and fear for ebola using twitter. Journal of Medical Internet Research, 19.

Van Tuijl, E., Carvalho, L. \& Van Haaren, J. 2013. Developing creative quarters in cities: policy lessons from 'Art and Design City' Arabianranta, Helsinki. Urban Research \& Practice, 6, 211-218.

Veil, S. R., Buehner, T. \& Palenchar, M. J. 2011. A Work-In-Process Literature Review: Incorporating Social 
Media in Risk and Crisis Communication. Journal of Contingencies \& Crisis Management, 19, 110-122.

Velasquez, A. \& Larose, R. 2015. Social Media for Social Change: Social Media Political Efficacy and Activism in Student Activist Groups. Journal of Broadcasting \& Electronic Media, 59, 456-474.

Velev, D. \& Zlateva, P. 2012. Use of social media in natural disaster management. ICITE Conference Hong Kong IPEDR, 39.

Vericat, J. 2010. Open source mapping as liberation technology. Journal of International Affairs.

Vieweg, S., Castillo, C. \& Imran, M. Integrating social media communications into the rapid assessment of sudden onset disasters. International Conference on Social Informatics, 2014. Springer, 444-461.

Vollmer, B. \& Karakayali, S. 2018. The Volatility of the Discourse on Refugees in Germany. Journal of Immigrant \& Refugee Studies, 16, 118-139.

Wachanga, D. N. 2015. Ethnic differences vs nationhood in times of national crises: The role of social media and communication strategies. Journal of African Media Studies, 7, 281-299.

Wade, F. (2017). Myanmar's Enemy Within: Buddhist Violence and the Making of a Muslim 'other', Zed Books.

Waldron, J. 2012. Conceptual frameworks, theoretical models, and the role of YouTube: Investigating informal music learning and teaching in online music community. Journal of Music, Technology \& Education, 4, 189200.

Walther, J. A. G., E. (EDITOR) 2012. Social informaton processing theory. A First look at communication theory, Mc Graw. Hill International Edition, 138-150.

Walther, Joseph B.1992. Interpersonal Effects in Computer-Mediated Interaction: A Relational Perspective. Communication Research. Vol 19, Issue 1, pp. 52 - 90, org.wam.leeds.ac.uk/10.1177/009365092019001003

Wanmohd Yaakob Wan Bejuri, M. M. M. R. Z. R. \& Radzi, M. 2015. A Proposal of Emergency Rescue Location (ERL) using Optimization of Inertial Measurement Unit (IMU) based Pedestrian Simultaneously Localization and Mapping (SLAM). International Journal of Smart Home, Vol. 9, No. 12, (2015), pp. 9-22, 9, pp. 9-22.

Watson, H. \& Hagen, K. 2015. An engaged public: Considerations for the use of social media in managing crises. Interactions: Studies in Communication \& Culture, 6, 141-154.

Webster, M. 2015. A practical guide for journalists reporting in Ukraine and other conflict zones. $\mathrm{http}$ //www.thomsonfoundation.org/latest/a-practical-guide-for-journalists-reporting-in-ukraine-and-otherconflict-zones/ retrieved in 24/07/18

Wei, W., Joseph, K., Liu, H. \& Carley, K. M. 2016. Exploring characteristics of suspended users and network stability on Twitter. Social Network Analysis and Mining, 6.

Weiss, A. S. (2013). Exploring news apps and location-based services on the smartphone. Journalism and Mass Communication Quarterly, 90, 435-456.

Wendling, C., Radisch, J. \& Jacobzone, S. 2013. The use of social media in risk and crisis communication.

Win, S. S. M. \& Aung, T. N. Target oriented tweets monitoring system during natural disasters. 2017 IEEE/ACIS 16th International Conference on Computer and Information Science (ICIS), 24-26 May 2017, 2017. 143148

Yates, D. \& Paquette, S. Emergency knowledge management and social media technologies: A case study of the 2010 Haitian earthquake. Proceedings of the 73rd ASIS\&T Annual Meeting on Navigating Streams in an Information Ecosystem-Volume 47, 2010. American Society for Information Science, 42.

Yoo, E., Rand, W., Eftekhar, M. \& Rabinovich, E. 2016. Evaluating information diffusion speed and its determinants in social media networks during humanitarian crises. Journal of Operations Management, 45, 123-133.

Yuan, W., Guan, D., Huh, E.-N. \& Lee, S. 2013. Harness Human Sensor Networks for Situational Awareness in Disaster Reliefs: A Survey. IETE Technical Review, 30, 240-247.

Zahra, K., Ostermann, F. O. \& Purves, R. S. 2017. Geographic variability of Twitter usage characteristics during disaster events. Geo-spatial Information Science, 20, 231-240.

Zhao, L., Yin, J. \& Song, Y. 2016. An exploration of rumor combating behavior on social media in the context of social crises. Computers in Human Behavior, 58, 25-36

Zin, M. 2015. Anti-muslim violence in burma: Why now? Social Research, 82, 375-397,553.

Zuckerman, E. 2010. International reporting in the age of participatory media. Daedalus, 139, 66-75,154.

Zwitter, A. 2015. Big data and international relations, Ethics \& International Affairs, 29, 377-389. 